\title{
A UTILIZAÇÃO DO GESTUAL COTIDIANO E ALGUNS DE SEUS DESDOBRAMENTOS NO ESPETÁCULO KONTAKTHOF (1978) DE PINA BAUSCH PARA O TANZTHEATER ${ }^{1}$ WUPPERTAL
}

\author{
Marina Milito de Medeiros \\ Professora substituta no Curso de Graduação em Dança da Universidade Federal de Alagoas \\ Doutoranda no Programa de Pós-Graduação de Arquitetura e Urbanismo da Universidade Federal de Alagoas \\ Email: marinamilito@yahoo.com \\ Sayonara Pereira \\ Professora na Escola de Comunicação e Artes da Universidade de São Paulo \\ Pós-Doutorado pela Freie Universitat Berlin (2016), Pós-Doutorado pela Universidade de Campinas (2009), \\ Doutorado em Artes pela Universidade de Campinas \\ Email: sayopessen@gmail.com
}

\section{Resumo}

O presente artigo pretende contextualizar o trabalho da coreógrafa e bailarina alemã, Pina Bausch (1940-2009), referência mundial do Tanztheater. Nosso recorte foca na análise da utilização do gestual cotidiano na obra de sua autoria Kontakthof. O espetáculo cênico foi criado em 1978 com bailarinos do Tanztheater Wuppertal e sua construção girou em torno dos conflitos inerentes às relações humanas, relações de poder, de carinho, de submissão, de descoberta e de exposição. Realiza-se uma análise das formas de utilização do gestual cotidiano no espetáculo cênico que, no ano 2000, teve uma remontagem com senhores e senhoras maiores de 65 anos e, em 2008, com alunos das escolas públicas da cidade de Wuppertal, todos sem nenhuma experiência profissional em dança. Suportam teoricamente este artigo as abordagens de autores como: Stanislavski, Brecht e Gil em diálogo com outras obras cênicas de Bausch.

Palavras-chave

Tanztheater. Pina Bausch. Kontakthof. Gestual Cotidiano.
Abstract

This article intends to contextualize the work of the German choreographer and dancer, Pina Bausch (1940-2009), a world reference of the Tanztheater. We have analyse the use of daily gesture in Bausch's work Kontakthof. The piece was created in 1978 with the Tanztheater Wuppertal dancers and its construction revolved around the human relations conflicts, such as power relations, affection, submission, discoveries and exposures. The analysis of the daily gestures uses is carried out in the piece that in the year 2000 had a new version with ladies and gentlemen over 65 years, and in 2008 with Wuppertal's public schools students, both cast without any professional dance experience. This article has the theoretical support of authors such as Stanislavski, Brecht and Gil, in dialogue with others Bausch's works.

Keywords

Tanztheater. Pina Bausch. Kontakthof. Daily gesture.

1 Tanztheater - Movimento de Dança que surgiu na Alemanha nos anos 1930 através de algumas proposições de Kurt Jooss (1901-1979) de somar à linguagem da dança clássica a dramaticidade do teatro e chegou aos nossos dias por meio dos trabalhos cênicos e da pedagogia das coreógrafas: Pina Bausch, Reinhild Hoffmann (1943), Susanne Linke (1944), entre outros (Pereira, 2007). 


\section{Introduzindo}

Philippine Bausch (Pina Bausch) nasceu em 1940, em Solingen, Alemanha. Iniciou muito cedo sua formação em ballet clássico e, aos 15 anos, foi estudar na escola Folkwang Hochschule ${ }^{1}$, na cidade alemã de Essen. Na mencionada escola, no período dirigida por Kurt Jooss (1901-1979)2, Pina Bausch obteve formação profissionalizante de quatro anos em dança. Em 1960, a bailarina foi contemplada pelo DAAD (Serviço Internacional Alemão de Intercambio Acadêmico) com uma bolsa para estudar na Julliard Scholl of Dance, Drama, Music, renomada escola de artes em Nova York (EUA). E, em 1973, aos 33 anos, assume o cargo de coreógrafa-residente da Ópera de Wuppertal. Ao assumi-lo, além de alterar o nome da Companhia de dança para Tanztheater Wuppertal (atualmente Tanztheater Wuppertal Pina Bausch), modifica vários paradigmas da dança existente e inaugura novas possibilidades para a dança, que seguem ecoando até os nossos dias. Bausch ocupou o cargo até seu falecimento, em junho de 2009.

Pina Bausch foi pupila de Kurt Jooss, mestre de quem recebeu forte influência e que a deixou livre para desenvolver cada vez mais suas próprias ideias. Em suas coreografias, Bausch passou a utilizar, a cada nova criação, mais elementos do teatro e de outras linguagens artísticas. Com uma abordagem muito própria, a jovem coreógrafa pôde também incorporar elementos da dança moderna americana e do teatro de vanguarda da década de 1960 dos Estados Unidos - período de estudos

\footnotetext{
1 Atualmente Folkwang Universität der Künste.
}

2 Coreógrafo e bailarino alemão, discípulo de Rudolf Laban e fundador da Folkwang Hochschule (Es-sen). É considerado precursor do Tanztheater (Medeiros, 2012). e vivências em Nova York, sempre em diálogo com elementos da tradição da dança moderna alemã.

Na Dança Teatral ${ }^{3}$, a personalidade, as histórias e as vivências dos intérpretes permeiam o processo de criação das obras. Bausch verticalizou seu trabalho nesse sentido, buscando expor o lado mais humano de seus bailarinos e quebrando a ideia de um bailarino idealizado que consegue fazer as mais diversas piruetas em nome de um virtuosismo técnico. Ela expõe, em suas peças, um bailarino humano, frágil, com dúvidas e inquietações, fazendo com que o público se identifique com o ser humano à sua frente. Os bailarinos do seu ensemble têm a liberdade de utilizar as diferentes técnicas corporais desenvolvidas ao longo de suas carreiras, mas as mesmas devem servir como meio para a expressividade e não como fim. Isso não quer dizer que seus bailarinos não sejam dotados de exímias qualidades técnicas.

O início do trabalho de Bausch com a companhia em Wuppertal não foi nada fácil. O público, acostumado a ver peças de ballet com bailarinas perfeitas, sempre sorrindo e mostrando suas capacidades virtuosas, talvez não estivesse preparado para entender as obras da coreógrafa e muitos saíam no meio do espetáculo, insatisfeitos. Mesmo assim, Bausch continuou desenvolvendo o trabalho artístico que acreditava e, quando o mundo passou a olhar suas criações com mais atenção e maior abertura, sua obra foi colocada em uma categoria de grande vanguarda e tem influenciado diferentes pessoas e artistas ao redor do mundo até os dias de hoje.

3 Dança Teatral - É a tradução para língua portuguesa mais apropriada para o termo Tanztheater segundo a autora Pereira (2007) e será usada por nós muitas vezes ao longo do texto. 


\section{Aproximações}

Para o desenvolvimento do presente artigo foram realizadas pesquisas bibliográficas, videográficas e pesquisa de campo. Tanto as metodologias empregadas quanto a escolha do espetáculo Kontakthof como objeto de estudo foram definidas em decorrência das vivências teórico-práticas da autora e da pesquisa de campo. Utiliza-se a metodologia de estudo de caso que, segundo Yin (2005), é ideal para responder às perguntas relacionadas a "como" e "porque", o que nos pareceu apropriado para responder à questão: "Como Pina Bausch utiliza o gestual cotidiano em Kontakthof?"

A pesquisa de campo (2010) incluiu: participação no workshop "Fortbildung mit Jo Ann Endicott" (Bremen), ministrado pela própria Jo Ann Endicott $(1950)^{4}$ - bailarina responsável pela coordenação das remontagens de Kontakthof, realizadas com senhoras e senhores e com adolescentes; acompanhamento dos ensaios de Kontakthof com adolescentes ${ }^{5}$; realização de entrevista semiestruturada ${ }^{6}$ com Meike Schuppenhauer, uma das jovens que participou da primeira versão de Kontakthof com adolescentes; observação do filme Tanzträume (2010) - documentário de Anne Linsel $(1942)^{7}$ que registra o processo de ensaio com os adolescentes até a estreia do espetáculo; observação do DVD de Kontakthof com se-

4 Bailarina australiana que começou a dançar com o Wuppertal Tanztheater em 1973, quando Pina Bausch assumiu a direção. Em 1987 deixou a companhia e em 1994 volta a trabalhar com Bausch como bailarina convidada e assistente (Endicott, 2009).

5 Festival Aperto, Reggio Emília, Itália, 2010.

6 Segundo Minayo (1996) combina perguntas fechadas e abertasem que o entrevistado tem a possibi-lidade de discorrer sobre o tema proposto, sem respostas ou condições prefixadas pelo pesquisador.

7 Jornalista e documentarista alemã. nhoras e senhores; pesquisa videográfica no Deutsche Tanzfilminstitut Bremen e no Deutsche Tanzarchive Köln, incluindo observação da gravação de Kontakthof realizado pelos bailarinos do Tanztheater Wuppertal na Haus Company $^{8}$ (2000). Ao longo da pesquisa de campo, observamos ao vivo os seguintes espetáculos do Tanztheater Wuppertal Pina Bausch: Danzón (1995) ${ }^{9}$, Kontakthof com adolescentes acima 14 anos $(2008)^{10}$, Nelken (1982) ${ }^{11}$, Ephigênia em Tauris (1973) $)^{12}$ e Água (2001) ${ }^{13}$. Observamos, ainda, outros quatro espetáculos da Companhia, ao vivo, em diferentes momentos que não o da pesquisa de campo: Ten Chi (2004) $)^{14}$, Das Frühlingsopfer (1975) ${ }^{15}$, Café Müller $(1978)^{16}$ e Für die kinder von gestern, heute und morgen (2002) ${ }^{17}$.

Para a análise das cenas selecionadas foram utilizadas ferramentas apontadas por Pavis em seu livro Análise dos espetáculos (2003), tendo como foco a utilização do gestual cotidiano dentro da obra Kontakthof (1978). Pavis aponta vários instrumentos para observação e análise, e pontos específicos comuns a todos os espetáculos que devem ser levados em consideração, muitos deles aqui utilizados, dentre os quais: descrição verbal, tomada de notas, do-

8 Fita 8990 - Deutsches Tanzfilminstitut Bremen.

9 Opernhaus Wuppertal, Wuppertal, Alemanha, 15/10/2010.

10 Festival APERTO, Teatro Valli, Reggio Emília, Itália, 09/10/2010.

11 Bienal de la Danse, Lyon, França, 16/09/2010.

12 Gran Liceu, Barcelona, Espanha, 04/09/2010.

13 Festival Internacional de Teatro, Edimburgo, Escócia, 29/08/2010.

14 Teatro Alfa, São Paulo-SP, 17/04/2011.

15 Teatro Alfa, São Paulo-SP, 2009.

16 Teatro Alfa, São Paulo-SP, 2009.

17 Teatro Alfa, São Paulo-SP, 2006. 
cumentos anexos, arquivo vivo, corpo "mediado" do espectador, trabalho do ator (bailarino/ intérprete), voz (música/ritmo), espaço, tempo, ação, figurino, iluminação, entre outros: "Esta reflexão sobre a análise dos espetáculos visa a esclarecer todas essas perspectivas e fornecer instrumentos simples e eficazes para receber e analisar um espetáculo" (Pavis, 2003, p. xvii).

\section{Kontakthof}

Kontakthof, pátio de contatos, lugar de encontro, espaço de troca, de busca pelo outro. Segundo Climenhaga (2009, p. 73), o termo traduzido do alemão pode tanto significar lugar de encontro, normalmente se referindo a pátios de escola ou de prisões, como local em que as prostitutas encontram seus clientes. $\mathrm{Na}$ própria escolha do título da obra, Bausch evidencia uma contradição, um paradoxo, abordagem essa recorrente nos trabalhos da coreógrafa, a qual Gil (2004, p. 171) denomina "lógica do paradoxo", que é também uma característica inerente aos seres humanos.

Kontakthof está entre os primeiros espetáculos do Tanztheater Wuppertal criados a partir de um tema e construído com o material trazido pelos bailarinos. Sua construção girou em torno dos conflitos inerentes às relações humanas, das relações de poder, de carinho, de submissão, de descoberta e de exposição. Segundo Bausch: "Ternura e o que nasce dela foram temas importantes no trabalho" (L'arche, 2007 , p. 8). ${ }^{18}$ Como estímulo para a criação coreográfica, foram feitas perguntas aos bailarinos, como: "O que é isso? Como alguém demonstra? Para onde vai? E quão longe a ter- nura pode ir? " (Climenhaga, 2009, p. 72). ${ }^{19}$

O espetáculo é extremamente teatral e utiliza movimentos simples e cotidianos, como colocar as mãos no bolso, esfregar as mãos, coçar a orelha, segurar os cabelos. Movimentos esses que, quando realizados em coro, ganham nova força e sentido. Praticamente toda a coreografia se constrói a partir de gestos cotidianos, estejam eles em sua forma realista, deslocados de seu sentido original, ou estilizados dentro de uma célula coreográfica.

Kontakthof foi apresentado pela primeira vez com os bailarinos do Wuppertal Tanztheater em 1978. No ano 2000, ou seja, vinte e dois anos depois de sua estreia, foi remontado em uma versão em que os intérpretes eram senhores e senhoras maiores de 65 anos sem nenhuma experiência profissional em dança. $E$ mais uma vez, trinta anos depois da primeira estreia mundial, no final de 2008, estreou outra versão do espetáculo, dessa vez realizada por adolescentes a partir de 14 anos de idade oriundos de diferentes escolas públicas da cidade de Wuppertal, também sem nenhuma experiência profissional em dança.

\section{— Um Gesto E Diferentes Definições}

"Um gesto vale mais do que mil palavras", já diria o velho ditado. Mas o que define o gesto? Qualquer movimento corporal pode ser considerado um gesto? Ou gestos são apenas movimentos corporais com uma codificação clara e comum a uma sociedade, os quais, quando realizados, imediatamente compreende-se seu significado? Pode-se considerar movimentos abstratos de dança como gesto? 
Gesto, segundo o dicionário Michaelis: "1 Movimento do corpo, principalmente das mãos, dos braços, da cabeça e dos olhos, para exprimir ideias ou sentimentos, na declamação e conversação: [...] 2 Forma de se expressar: [...] 3 V gesticulação." ${ }^{20}$ De acordo com o coreógrafo e importante pesquisador do movimento humano, Rudolf Von Laban (1879-1958), "Os gestos são ações das extremidades, que não envolvem nem transferência nem suporte de peso. Podem dar-se em direção ao corpo ou para longe dele" (Laban, 1978, p. 60).

Lehmann, em suas conceituações sobre o teatro pós-dramático, define o gesto como:

O gesto é aquilo que fica em suspenso em cada ação voltada para um objetivo: um excedente de potencialidade, a fenomenalidade de uma visibilidade como que ofuscante, que ultrapassa o olhar ordenador - o que se torna possível porque nenhuma finalidade e nenhuma reprodutibilidade enfraquece $o$ real do espaço, do tempo e do corpo. O corpo pós-dramático é, nesse sentido, um corpo do gesto. (Lehmann, 2007, p. 342).

Mary Wigman (1886-1973) ${ }^{21}$, a grande dama da dança de expressão alemã, utiliza o termo "Gesto expressivo", ausdruck-gebarde no original alemão, para definir seu recurso de utilização do gesto em cena. Em suas coreografias, buscava expressar emoções individuais a partir de movimentações que fizessem alusões a gestos cotidianos, porém distorcidos, estili-

20 Disponível em: http://michaelis.uol.com.br/busca?r=0\&$\mathrm{f}=0$ \& $\mathrm{t}=0$ \&palavra=gesto. . Acesso em: 14/04/17.

21 Bailarina alemã considerada um dos ícones da German Dance e representante da dança de ex-pressão a partir do início do século XX. Estudou na Escola de Hellerau/Dresden sob a direção de Émile Jaques-Dalcroze (1865-1950) e posteriormente foi aluna e assistente de Rudolf Von Laban (18791958) na sua escola no Monte Veritá na Suíça. Suas obras cênicas tratam da condição humana e algumas delas podem ser vistas até os dias de hoje através de remontagens (Pereira, 2007). zados, indo além de seus significados habituais. Wigman buscava expressar algo interno, indizível (Climenhaga, 2009). Essa foi uma busca comum entre os representantes da dança moderna alemã, a estilização do movimento para expressão de estados interiores, abordagem muito presente também no trabalho de Bausch.

$\mathrm{Na}$ busca de uma dança mais expressiva, Pina Bausch começa a construir seus espetáculos a partir do material trazido por seus bailarinos. Ela passa a se inspirar no cotidiano e pede para eles se observarem e observarem também seu entorno na busca de respostas poéticas para suas perguntas. Assim, gestos cotidianos ou figurativos voltam à cena, entretanto sem a referência do modelo Aristotélico de unidade de tempo. Esses gestos não vêm necessariamente em função de uma fábula ou de uma narrativa linear ${ }^{22}$ que pretende ser contada para o público. Na obra de Bausch, o gesto cotidiano é utilizado nas mais variadas formas com o intuito de suscitar emoções que possam ir além do gesto em si mesmo e da sua utilização usual: "[...] Mudar a dança do nível da abstração estética para um comportamento físico cotidiano não é simplesmente uma questão de estilo - também mudou o próprio significado da dança" (Servos, 2008, p. 22).

\footnotetext{
22 Considera-se "narrativa linear" o modelo Aristotélico de unidades de tempo baseado em um sistema de causa e efeito em que cada ação tem uma reação, e elas estão organizadas em ordem crono-lógica de acontecimento, devendo apresentar um início, um meio e um fim e abranger uma peripécia e uma conclusão, um desfecho dela. "A poética de Aristóteles concebe a beleza e o ordenamento da tragédia segundo a analogia com a lógica. Assim, são concebidos segundo o padrão do lógico os termos de que a tragédia tem que ser um 'todo' com começo, meio e fim, ligados à exigência de que a 'grandeza' (a extensão temporal) deve abranger precisamente o bastante para uma peripécia e a partir daí para a catástrofe conclusiva" (Lehmann, 2007, p. 63).
} 


\section{Gesto cotidiano}

O gesto cotidiano é aquele utilizado no dia a dia, gesto simples e que, em geral, não significa nada além de si mesmo. Quando se cumprimenta uma pessoa com um aceno, a finalidade, o significado desse gesto está inserido nele mesmo, não quer dizer nada além de um cumprimento. Esse movimento é codificado e reconhecido em determinada sociedade com seus hábitos sociais específicos. O significado de cada gesto e de cada movimento está diretamente relacionado à sociedade em que o mesmo está inserido.

Os gestos cotidianos realizam-se, em geral, de maneira consciente e com intuitos claros, se alguém penteia o cabelo é porque quer desembaraçá-lo, ou seja, são gestos funcionais, são ações com finalidades específicas.

Entretanto, pensando em termos de interpretação para o teatro, existem mil maneiras de se pentear um cabelo e, para cada uma, pode-se dar uma leitura diferente. Pentear o cabelo com movimentos leves e desacelerados e com o olhar vago e distante (espaço indireto ${ }^{23}$ ) pode gerar uma leitura de sonho ou de lembrança. Mas, se utilizarmos para a realização do mesmo gesto qualidades de movimento opostas, ou seja, pentear o cabelo com movimento direto, forte e acelerado, pode gerar uma leitura de raiva ou revolta. Segundo Laban (1978), todo movimento humano é expressivo, logo, até mesmo por meio de gestos funcionais do cotidiano se exprimem estados da alma. Esse foi um dos focos de trabalho dos artistas e pesquisadores das artes da cena da primeira metade do século XX no ociden-

23 Características referentes às qualidades expressivas dos fatores de movimento sistematizados por Rudolf Von Laban (FERNANDES, 2006). te - desenvolver métodos que possibilitassem ao intérprete moldar seu corpo, seus gestos, suas ações para expressar os estados de alma adequados à cena. O grande estudioso do teatro, Constantin Stanislavski (1863-1938) ${ }^{24}$, denomina como "ação física" a ação realizada da maneira adequada à expressão da personagem.

Na vida, no dia a dia, as pessoas são constantemente atravessadas por diferentes sentimentos, porém, além desses sentimentos, têm-se "funções" sociais, obrigações a cumprir. Assim, mesmo que inconscientemente, o ser humano demonstra seus sentimentos por meio das pequenas ações, dos pequenos gestos cotidianos, por meio das diferentes qualidades de movimento com que se realiza cada um desses gestos.

\section{Três diferentes tipos de gesto}

Observam-se três formas recorrentes de utilização do gestual cotidiano em Kontakthof: realista, deslocada e estilizada. Denominamos, respectivamente, Gesto realista, Gesto deslocado e Gesto estilizado e, para cada uma dessas abordagens, traçamos um paralelo com conceitos desenvolvidos anteriormente por três autores, a saber: Constantin Stanislavski, Bertold Brecht (1898-1956) ${ }^{25} \mathrm{e}$

24 Ator e diretor teatral russo, fundador do Teatro de Arte de Moscou. Teve seu trabalho diretamente ligado à obra do escritor russo Anton Tchekhov ao montar suas peças. Desenvolveu um sistema para a preparação de ator e interpretação teatral muito utilizado até os dias atuais em todo o ocidente (STANISLAVSKI, 2003b).

25 Dramaturgo e poeta alemão fundador do "Teatro Épico" teatro político que pretende, através da utilização do recurso do distanciamento, que a plateia desenvolva um pensamento crítico sobre a situação apresentada (MIRANDA, 2011). 
José Gil (1939) ${ }^{26}$. Relaciona-se o Gesto realista ao conceito de Ação física, desenvolvido por Stanislavski (2003a), o Gesto deslocado ao conceito de Estranhamento, desenvolvido por Brecht (2005) e o Gesto estilizado ao conceito de Gesto dançado, apresentado por Gil (2004).

\section{Gesto realista}

Segundo Stanislavski, a ação física seria a ação realizada por um personagem, coerente com as circunstâncias dadas pelo texto ou pelo diretor. Ou seja, se a indicação é de que o personagem está atrasado e nervoso, o ator deve escolher a maneira adequada de realizar suas ações para que possa comunicar essas duas "circunstâncias dadas" ao público (Stanislavski, 2003a). Os estudos de Stanislavski foram desenvolvidos para interpretação de personagens realistas, dentro de um teatro realista, que buscava ao máximo se aproximar de uma representação da vida em cena. Portanto, consideramos aqui como Gesto realista, aquele colocado em cena em sua forma "pura", ou seja, "como na vida real". Vê-se no palco uma "cena teatral" como se fosse uma fatia da vida representada no palco.

Essa é uma abordagem do gesto que, tradicionalmente, estaria ligada ao teatro e não à dança. Originalmente, segundo o modelo clássico de dança, mesmo que a coreografia fosse mais "figurativa" e estivesse em função de uma fábula ou narrativa, o gesto realista seria transformado e estilizado em célula coreográfica para que se conseguisse contar a história pretendida de maneira "dançada": "Em

26 Filósofo português, professor da Universidade Nova de Lisboa, considerado em Janeiro de 2005 pela revista francesa Nouvel Observateur como um dos 25 grandes pensadores do mundo (Lopes, 2005). algumas danças os gestos podem referir-se a estados emocionais determinados, podendo a sua sequência contar uma história" (Anderson, 1987, p. 9).

Nos modelos atualmente vigentes, tanto na dança quanto no teatro, já não existem padrões tão definidos, mas em 1978, quando Bausch coloca em Kontakthof bailarinas sentadas em um cavalinho de brinquedo como se estivessem em um parque de diversões ou um dos bailarinos fotografando casais no palco e depois oferecendo a fotografia para a plateia, isso foi surpreendente no universo da dança e muitas vezes não agradava ao público, o qual teria ido ao teatro esperando ver "Dança", e não "Teatro". As pessoas se perguntavam: "Onde estão as coreografias ou o corpo de baile?". Pina Bausch nunca impôs limites de linguagens para si ou para o seu ensemble: para ela tudo poderia ser dança.

Nas obras de Bausch, mesmo quando o gesto é usado de maneira realista, não será a obra inteira dessa maneira, "à la Stanislavski". O Gesto realista aparece em um momento específico e dialoga com a cena que o antecedeu - que pode ter sido, por exemplo, uma grande coreografia ou uma conversa com a plateia, bailarinos cantando uma canção ou um vídeo falando sobre o acasalamento dos patos selvagens. E dialoga também com a cena que vem em seguida ou com uma cena que está acontecendo concomitantemente. Esse "diálogo", essa relação entre as cenas, é feito por associação, e não por uma lógica Aristotélica de causa e efeito comum ao teatro realista.

Uma das cenas de Kontakthof em que observamos a utilização do Gesto realista é a cena do "cavalinho" na qual uma das bailarinas se dirige à plateia, pede uma moeda para uma das pessoas do público e caminha até 
um cavalinho de brinquedo localizado no canto esquerdo do palco, senta-se nele e insere a moeda para fazê-lo funcionar.

Figura 1: senhora sobre cavalinho inserindo moeda. Versão realizada pelos senhores e senhoras.

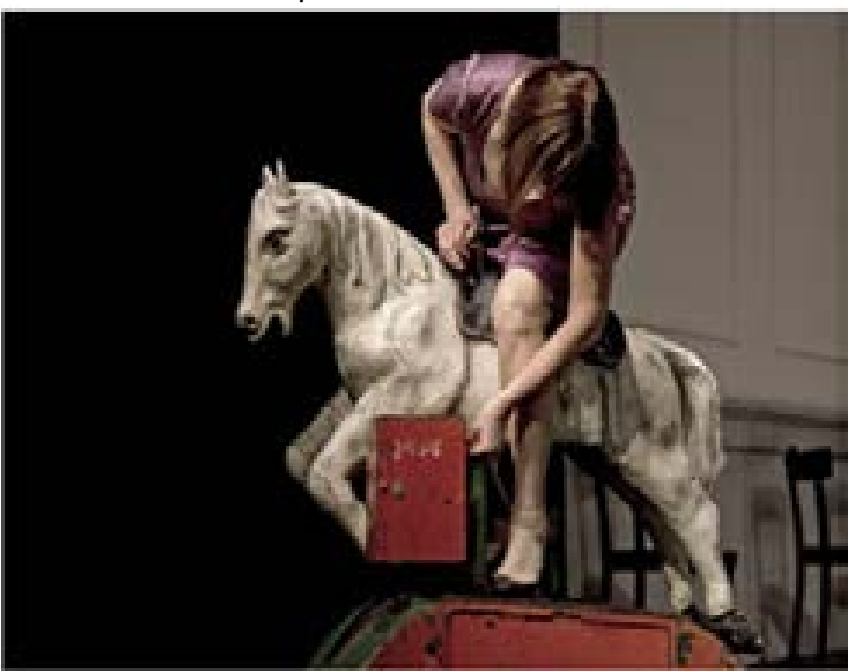

Fonte: Acervo Tanztheater Wuppertal Pina Bausch ${ }^{27}$

A cena em si se realiza de maneira "realista", ou seja, "como se" fosse na vida real. A bailarina se coloca de maneira cotidiana, tanto ao pedir a moeda quanto na relação com o brinquedo. Porém, a cena anterior a essa foi o hip-step, cena em que todo o elenco junto, de frente para a plateia, rebola caminhando para frente e às vezes rebolam de costas, destacando as nádegas.

O fato da cena do cavalinho vir logo após o hip-step já a coloca de maneira deslocada no contexto geral do espetáculo, mesmo sendo ela realizada de maneira realista. Além disso, enquanto a bailarina se coloca no cavalinho, um homem traz para o palco uma das muIheres de braços dados e a deixa na boca de cena. Ela, de olhos fechados, começa a fazer pequenas carícias em si mesma. Essa atitude gera na plateia uma sensação de solidão, que é ampliada pela presença da outra bailari-

27 Todas as imagens estão disponíveis em http://www.pina-bausch.de/. Acesso em: 13/04/2017. na sentada no cavalinho que não funciona do lado oposto do palco.

Figura 2: Hip-step realizado pelo elenco de adolescentes.

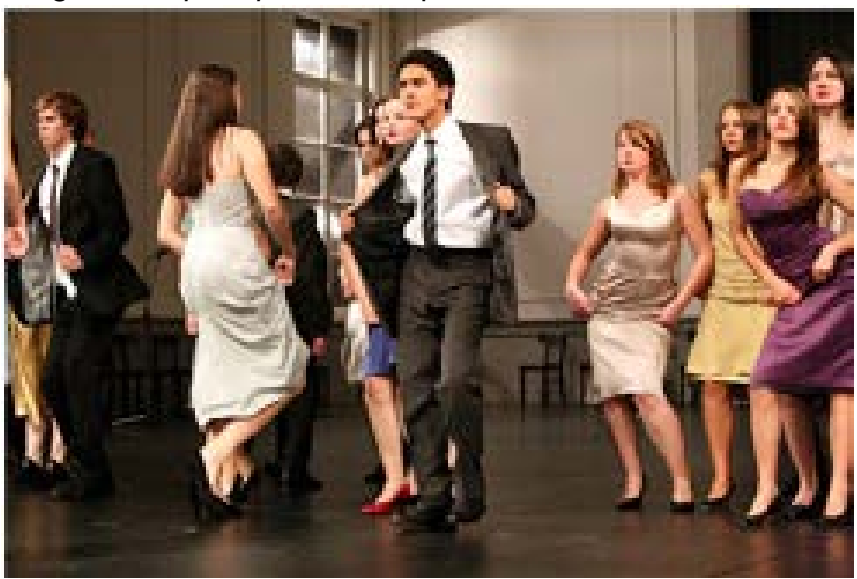

Fonte: Acervo Tanztheater Wuppertal Pina Bausch.

Quando o cavalinho não funciona a bailarina retorna ao público para pedir outra moeda, gerando um efeito cômico que deixa o público mais vulnerável, mais aberto e sensível ao abandono das mulheres que estão se posicionando sozinhas pelo palco de olhos fechados e se acariciando. Acreditamos que o efeito do cômico, por sua capacidade direta de emocionar, proporciona ao espectador uma maior abertura para o drama.

Finalmente, depois de algumas tentativas frustradas de fazer o cavalinho funcionar com moedas, a bailarina chama um dos bailarinos que "descobre" que o brinquedo estava fora da tomada. Ela pede mais uma moeda ao público e desta vez monta no cavalinho e consegue fazê-lo funcionar. Aos poucos, outras bailarinas pedem moedas para um dos bailarinos e começam a fazer uma fila para brincar no cavalinho. Toda a cena é realizada de maneira realista, apesar de estar totalmente deslocada de seu contexto original - o parque de diversões. Os gestos, as ações e a cena são construídos de maneira realista, porém, pode-se dizer que a cena causa um estranhamento 
quando vista do macrocosmo do espetáculo, pois está completamente deslocada de seu lugar comum.

De acordo com observação realizada é da maneira acima descrita que encontramos o Gesto realista em Kontakthof. Ou seja, apesar de realizado com uma interpretação realista, no contexto geral do espetáculo, pode-se dizer que o Gesto realista está deslocado - contrastando com a cena anterior e/ou com a que vem a seguir. Outras vezes ainda o mesmo será realizado concomitante a uma ou mais cenas. Portanto, o Gesto realista na obra de Bausch está sempre em diálogo com outras cenas que extrapolam o realismo - criando uma leitura da cena que emerge dessa relação.

Apesar de Bausch e Stanislavski utilizarem o Gesto realista de maneiras diferentes em suas obras, parece que ambos tinham a mesma preocupação, qual seja, a de que o gesto em cena se realizasse de maneira "verdadeira" ou, em outras palavras, que fosse realizado a partir de um impulso interno. Bausch costumava afirmar: "O que me interessa não é como as pessoas se movem, mas sim o que as move"28. O diretor Stanislavski parece defender o mesmo com diferentes palavras:

Assim, os impulsos interiores - o ímpeto de agir e as ações interiores propriamente ditas - adquirem em nosso trabalho uma importância excepcional. São nossa força motriz nos momentos de criação, e só é cênica a criatividade que se fundamenta na ação interior. (Stanislavski, 2003a, p. 70).

28 Disponível em: http://www.dw.com/pt-br/pina-bausch-tudo-\%C3\%A9-dan\%C3\%A7a/a-1682335. Acesso em: 13/04/2017.

\section{Gesto estilizado}

Gil (2004) utiliza o termo "Gesto dançado" para o movimento dançado independente de significados prévios ou de gestos cotidianos. Nesse caso, observamos de que maneira Bausch utiliza o gestual cotidiano como elemento para composição coreográfica do Gesto dançado, do Gesto estilizado:

Todos esses movimentos (signos indicativos) se fundem e se inserem no movimento dançado, de tal modo que "o gesto dançado de indicar" contém nele os movimentos da emoção, do pensamento, da visão, etc. Ảgora é todo o corpo em ação que é o sentido do signo: o corpo não significa o gesto de apontar o dedo para um pássaro que voa, e o movimento do sentido (ou da gênese do sentido) que o gesto, na sua forma estática, condensava nele. (Gil, 2004, p. 97-98).

Nessa abordagem Bausch se aproxima da tradição figurativa clássica, em que o gestual cotidiano era estilizado dentro de uma célula coreográfica, porém, sem a antiga necessidade de uma narrativa fabular. Em suas obras, a estilização vem em função da expressão, e não da figuração. Por exemplo, em Kontakthof, na cena em que os intérpretes começam a caminhar em círculo, todos no mesmo ritmo e fazendo uma sequência de pequenos gestos com as mãos na altura do quadril - polegares para fora, mãos no bolso da calça, uma mão pega na outra à frente do corpo, depois as mãos se pegam nas costas, olhar para trás, mãos na cintura, conta 1, 2, 3, 4 com os dedos, do mínimo ao indicador, esfrega uma mão na outra, conta novamente, 1, 2, 3, 4 com os dedos, mexe na orelha, enche as bochechas de ar como um balão e recomeçam a sequência sempre caminhando em círculo e olhando para 
o público com um meio sorriso. Todos realizam os movimentos juntos, como uma coreografia, fazendo com que se veja poesia em cada um desses gestos usados cotidianamente e que são tão "insignificantes". O fato de serem realizados em grupo e em sincronia dá mais força ao movimento e gera certa comicidade. ${ }^{29}$

Podem-se observar células coreográficas análogas a essa em outros espetáculos da coreógrafa em que ela seleciona pequenos gestos, só com as mãos e braços e, às vezes, com a cabeça, realizados pelos bailarinos juntos, em fila, em linha ou, como no caso acima citado, em círculo. Na obra Nelken (1983) são vistas repetidas vezes os bailarinos entrarem em uma fila fazendo quatro gestos que "representam" ou mimetizam, de maneira ingênua e quase infantil, as quatro estações do ano: inverno, primavera, verão e outono.

Figura 3: "Trenzinho" do espetáculo Nelken realizado no filme Pina (2010) de Win Wenders.

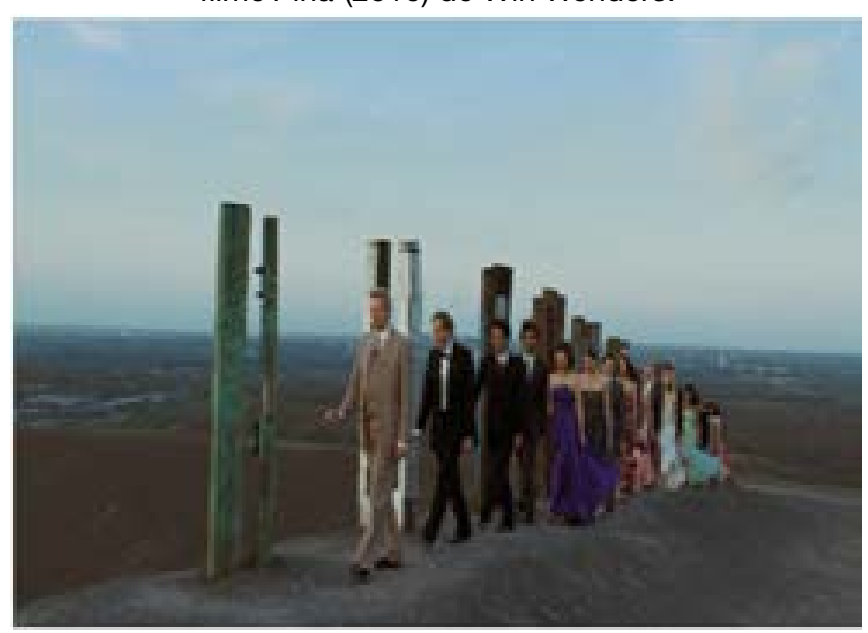

Fonte: Acervo Tanztheater Wuppertal Pina Bausch.

Na peça 1980 (1980) também se vê uma fila de bailarinos realizando gestos iguais simultaneamente, desta vez os gestos são mais abstratos, porém, o princípio é o mesmo das duas outras coreografias. Os bailarinos entram algumas vezes durante o espetáculo realizando juntos esses gestos e sempre acompanhados pela mesma música, e, em fila, caminham também pela plateia. Nesse caso, a célula se repete algumas vezes ao longo do espetáculo, como um Leitmotiv.

Nos exemplos acima citados, a célula coreográfica é formada quase inteiramente de pequenos gestos que envolvem, em sua maioria, somente os braços, a cabeça e um pouco do tronco. Porém, também se observa outra forma de utilização do Gesto estilizado nas coreografias de Bausch. No meio de uma célula coreográfica mais vigorosa, que se poderia chamar de uma célula de "dança pura", onde todo o corpo do intérprete está envolvido nas ações, veem-se giros, movimentos ágeis com as pernas, movimentos com alta exigência de equilíbrio, mudanças de plano ${ }^{30}$ e de peso. E no meio desse turbilhão, em que o encantamento acontece pela simples beleza do movimento, vê-se um gesto que se reconhece (figurativo ou funcional) e depois não se vê mais, pois agora este se transforma em dança novamente. $\mathrm{O}$ gesto aparece no meio do movimento quase como um flash e, em seguida, transforma-se novamente em um belo movimento dançado. Este "belo movimento dançado" talvez seja o que Brecht na citação a seguir acredita ser a coreografia:

Evidentemente, é necessário que a estilização não suprima a naturalidade do objeto, mas, sim, que a intensifique. Porém, seja qual for o caso, a verdade é que um teatro que tudo extrai do gesto não pode prescindir da coreografia. (Brecht, 2005, p. 164).

29 Disponível em: https://www.youtube.com/watch?v=eTCcRutPxZE. Filmagem na íntegra de Kon-takthof realizado com senhores e senhoras. Acesso em: 13/04/2017.

30 Plano horizontal, vertical ou sagital (Fernandes, 2006). 
Observa-se algo análogo no solo que Bausch dança ${ }^{31}$ no espetáculo Danzón (1995). Porém, o mesmo se realiza com movimentos lentos e contínuos, no qual, praticamente, apenas os braços e o tronco são os protagonistas das ações, característica muito comum na caligrafia da criadora. A coreógrafa realiza de olhos fechados uma sequência de movimentos abstratos muito leves, lentos e contínuos. Seus movimentos emanam beleza e poesia por si só. Ao fim da célula coreográfica, vê-se emergir de seus longos braços dançantes um aceno, um adeus de olhos abertos. E esse pequeno gesto cotidiano surge com muito mais força porque se seguiu à sequência de movimentos abstratos, e o pequeno detalhe de os olhos se abrirem salta à vista. Tudo isso perfeitamente acompanhado pela música de origem portuguesa, que parece quase chorar junto com a bailarina. Ao fundo, através de uma projeção, vemos peixes nadando em um aquário, navegando em diálogo com a movimentação arrebatadora de Bausch.

Figura 4: solo de Pina Bausch em Danzón (1995).

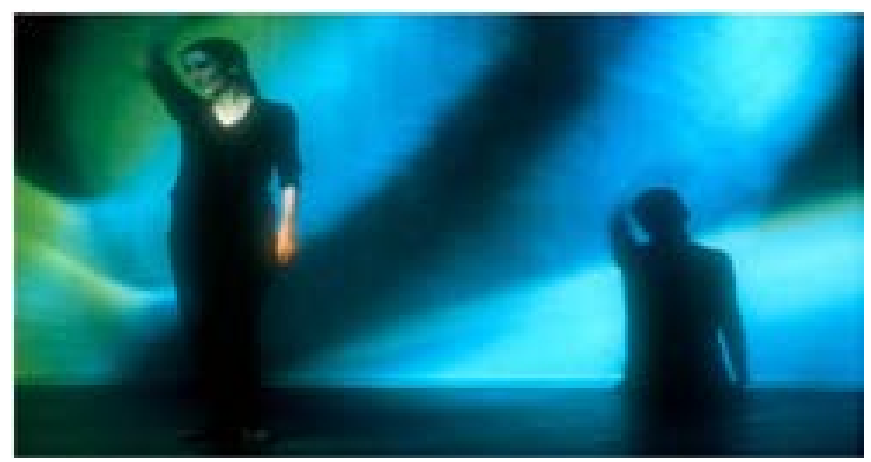

Fonte: Acervo Tanztheater Wuppertal Pina Bausch.

31 Pina Bausch dançava apenas em dois espetáculos da Companhia: Café Müller (1978) e Danzón (1995). Assistimos Danzón em 2010, na Opernhaus Wuppertal e, na ocasião, o solo de Pina Bausch foi realizado pelo jovem bailarino da Companhia, Aleš Čuček.

\section{Gesto deslocado}

Considera-se aqui Gesto deslocado quando se utiliza um gesto cotidiano fora de seu lugar original, ou seja, deslocado de sua utilização no dia a dia, gerando um estranhamento na plateia: "Numa reprodução em que se manifeste o efeito de distanciamento, o objeto é suscetível de ser reconhecido, parecendo, simultaneamente, alheio" (Brecht, 2005, p. 145). Por exemplo, no espetáculo Água (2001), quando a bailarina Regina Advento (1965) ${ }^{32}$ pega uma escova de cabelo e penteia todo o corpo. A ação de pentear é cotidiana, mas causa um estranhamento, porque a bailarina extrapola essa ação. A ação sai de uma dimensão funcional e ganha uma dimensão poética: "Coisas que viraram uma segunda natureza na vida cotidiana podem agora ser percebidas pela primeira vez distanciadas, o que é permitido por um novo estranhamento" (Servos, 2008, p. 26).

Bausch se utiliza do gestual cotidiano deslocado, ressignificando a relação com cada pequeno gesto, cada pequeno movimento e com cada um dos sentimentos que os suscitam. Quando se vê em Kontakthof um grande grupo, unido, de frente para o público, rebolando e avançando, ora rebolando de costas, para depois tornar a rebolar de frente, sempre avançando em direção à plateia, sempre no ritmo da música (cena do hip-step), esse gesto, essa ação, está completamente deslocado de seu contexto original. O rebolar para frente é colocado quase como uma marcha e atinge um lugar poético próximo à estética do absurdo e talvez por isso seja tão interessante. É improvável, surpreendente e pega o espectador desprevenido.

32 Brasileira, bailarina do Tanztheater Wuppertal Pina Bausch desde 1993. Disponível em: http://www.pina-bausch. de/tanztheater/ensemble/advento regina.php. Acesso em: $13 / 04 / 2017$ 
Rebolar é um movimento que, em geral, está relacionado à sexualidade, ao jogo da conquista, símbolo de um despudor e, por conseguinte, envolto por muitos "tabus" sociais. Por ser um "tabu", em geral não se trata de maneira aberta ou cotidiana esse movimento. Bausch faz justamente o oposto: coloca um "exército" de bailarinos realizando a sua "marcha rebolado" como se fosse a coisa mais normal do mundo, o que torna a situação absurda e provoca o efeito de estranhamento. O que se pode associar com o pensamento de Brecht (2005, p. 160), a seguir:

Apresentado deste modo, o acontecimento único e especial assume um aspecto "estranho", pois surge como algo geral, algo que se tornou um costume. Já o fato de se perguntar se é ao próprio acontecimento, ou a qualquer aspecto dele, que deverá ser dado o alcance de um costume, distancia esse acontecimento.

No início de Kontakthof vê-se uma cena análoga, em que os intérpretes estão mais ou menos na mesma formação da cena acima citada (hip-step), ou seja, bem próximos, em grupo, centralizados no fundo do palco e de frente para a plateia. Desta vez os intérpretes começam a caminhar para frente com um passo que cruza uma perna sobre a outra e deixa o quadril cair para o lado, remetendo à ação de sentar. E assim caminham para frente realizando, todos juntos e em coro, as seguintes ações com a perna direita: "chuta, cruza, dobra e abre", em uma movimentação equivalente à da "secretária" sentando na cadeira.
Figura 5: passo da secretária realizado pelo elenco de bailarinos do Tanztheater Wuppertal.

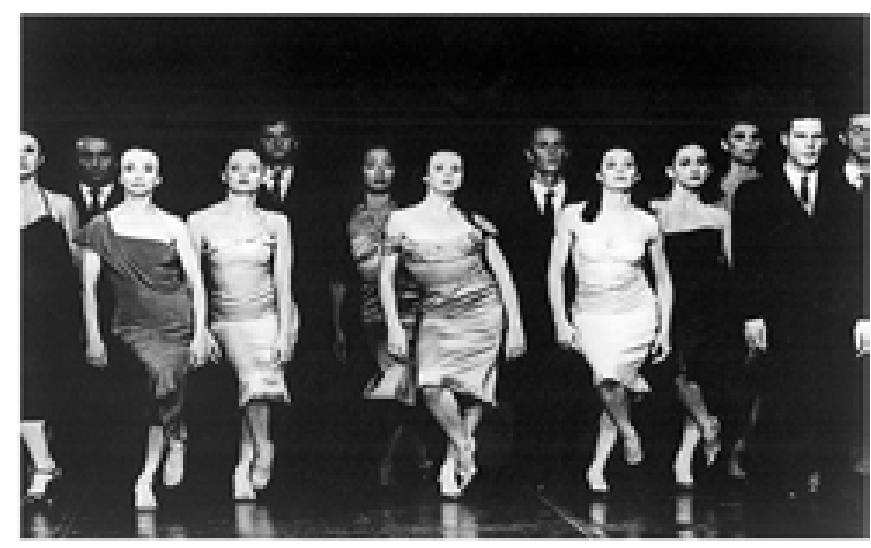

Fonte: Acervo Tanztheater Wuppertal Pina Bausch.

Novamente a cena se torna ainda mais interessante pelo fato de os intérpretes não demonstrarem grandes reações. Realizam os movimentos de maneira quase blasée, sem expressão facial. Aqui, Bausch utiliza mais um dos elementos necessários ao efeito de distanciamento apontado por Brecht (2005, p. 115): "A poesia devia estar, talvez, mais nas situações do que na expressão das personagens que reagem às situações".

A expressão facial é um recurso de extrema importância para a construção do Gesto deslocado na cena de Bausch. Na verdade, é interessante notar como a expressão facial é milimetricamente definida no trabalho da coreógrafa. $\mathrm{O}$ intérprete nunca está com o rosto "vago"; cada ângulo e cada expressão são precisos. Segundo as indicações de Endicott no workshop ministrado em Bremen e como aponta Bausch no documentário Tanzträume (2010), nas duas cenas acima citadas (hip step e secretária) a indicação é para que os intérpretes façam a expressão facial que no grupo é chamada de pocker face, essa expressão facial requer certa neutralidade, quase sem nenhuma expressividade, muitas vezes contrastando com os movimentos realizados pelo corpo. 
Em Kontakthof, na cena anteriormente citada, onde os bailarinos formam um círculo e realizam pequenos gestos com as mãos, os intérpretes devem olhar para o público com um meio sorriso, sugerindo "uma paquera". Em algumas diagonais, os olhos e a cabeça devem apontar para a diagonal esquerda alta. $\mathrm{Na}$ dança das pink girls ${ }^{33}$ os olhos e os sorrisos dançam com as intérpretes. Até a angulação do olhar é definida para assegurar o resultado desejado pela coreógrafa.

Figura 6: cena das "Pink girls" realizada pelo elenco de senhores e senhoras.

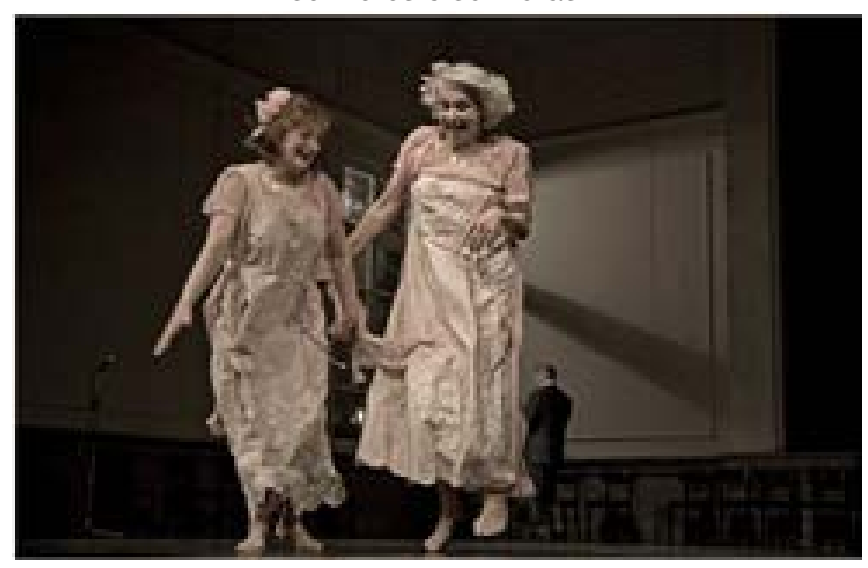

Fonte: Acervo Tanztheater Wuppertal Pina Bausch.

O estranhamento pode ser gerado tanto pelo deslocamento do gesto quanto pela relação entre o movimento e a expressão facial. Em uma das cenas de Kontakthof, casais começam a ir para frente do palco a fim de fazer uma espécie de apresentação de seus companheiros, e começam a fazer pequenas agressões um ao outro, apresentando-as como em um número de circo. Apesar da "dor", o casal continua sempre sorrindo, mantendo uma máscara social, e segue nessa apresentação de "horrores", puxões no nariz, aperto no bico do seio, pisada no pé entre outros.

33 Dueto de bailarinas com vestidos rosa esvoaçante dançando pelo palco nessa brincadeira de dan-çar com o olhar indireto, na diagonal.
Se a cena fosse apresentada de outra maneira, se o casal simplesmente aparecesse brigando, isso poderia causar um desconforto na plateia, e não necessariamente um estranhamento. Seria uma cena possível de se encontrar na vida real, pois casais brigam e muitas vezes se agridem física e/ou verbalmente. Observando uma cena realista de briga entre casal, o espectador pode se colocar em um ponto de vista passivo e se isentar, como se aquilo estivesse acontecendo com aquele casal, logo, não diz respeito a ele. Porém, acreditamos que no momento em que essas agressões são colocadas de maneira deslocada e, mais do que isso, literalmente apresentadas para o público como um "grande ato", tornam-se simbólicas e são redimensionadas. A partir de então elas se tornam um símbolo de todas as pequenas "agressões" feitas pelos indivíduos, uns aos outros todos os dias, em pequenas descortesias que, aos poucos, vão se estabelecendo nas relações cotidianas. Brecht intensifica este pensamento ao afirmar:

O objetivo do distanciamento é distanciar o "gesto social" subjacente a todos os acontecimentos. Por "gesto social" deve entender-se a expressão mímica e conceitual das relações sociais que se verificam entre os homens de uma determinada época. (Brecht, 2005, p. 109).

Figura 7: cena das "agressões", na versão realizada por adolescentes.

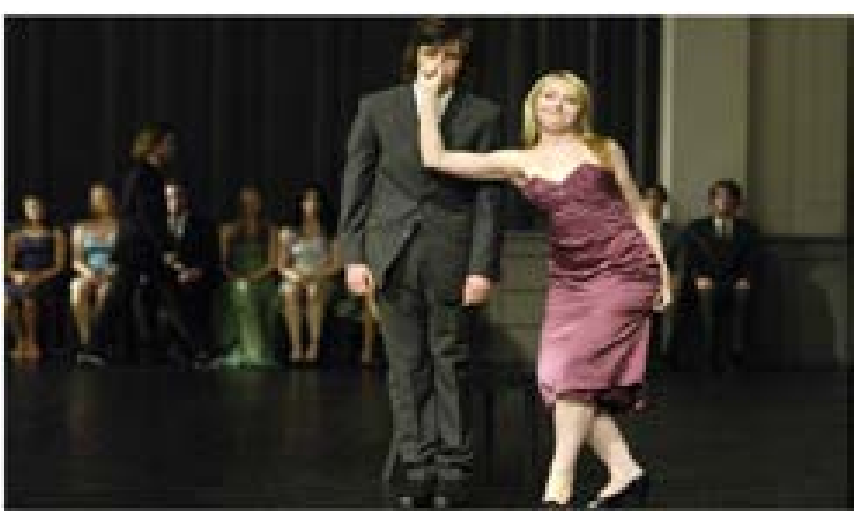

Fonte: Acervo Tanztheater Wuppertal Pina Bausch. 
As agressões são espetacularizadas, causando o distanciamento necessário para estimular a reflexão e o posicionamento crítico do espectador. Abordagem oposta ao arrebatamento emocional provocado pela identificação em uma estética realista das artes cênicas. Segundo Brecht (2005, p. 126), "Seria demasiado difícil, por exemplo, apresentar a teoria do distanciamento fora de uma perspectiva estética".

\section{Considerações Finais}

Kontakthof é construído a partir de questionamentos sobre ternura e suas decorrentes relações humanas, mas a ternura não é exposta apenas em sua abordagem mais óbvia de carinho e suavidade, e sim em suas diversas facetas e desdobramentos, algumas delas nem sempre agradáveis. O espetáculo utiliza um modelo de colagem de cenas e de livre associação, recorrente nas obras da coreógrafa. Não assistimos a uma narrativa linear, porém as cenas, de alguma maneira, têm uma unidade entre si e constroem uma mesma atmosfera. Estão sempre "falando" sobre o mesmo tema: as relações humanas, o desejo e a dificuldade dos Homens de se encontrar e todas poderiam, de fato, acontecer em um salão de baile ou em um café: "[...] Mas você sabe, meus pais tiveram um restaurante, eu estava sempre lá. Era um restaurante de bairro, não um restaurante elegante - mas um lugar onde a vida acontece, onde casais têm brigas e casos de amor [...]" (Bausch, Pina) ${ }^{34}$.

A obra original Kontakthof é uma das pri- meiras peças de Bausch com o Tanztheater Wuppertal, na qual ela explora com maestria aspectos das contradições humanas, tornando, assim, a obra multifacetada e sempre reatualizada.

Outro fato a ser ressaltado é que a obra vem sendo apresentada há quase 40 anos sem perder sua força e qualidade dramática, independente de qual dos três elencos a executa. De 1978, ano de sua estreia, até a atualidade muitas coisas mudaram, o mundo mudou. Passamos por uma Revolução Digital, o teatro, a dança, os conceitos de arte mudaram, mesmo assim Kontakthof em toda sua gestualidade, sensibilidade e humor, mantém o seu frescor e jovialidade. Pode-se afirmar que a cada remontagem é possível (re) descobrir novas cores e inspirações para esta obra tão emblemática de Pina Bausch em diálogo com os seus intérpretes-colaboradores.

Referências

ANDERSON, Jack. Dança. Tradução: Maria da Conceição Ribeiro Costa. Lisboa-São Paulo: Editorial Verbo, 1987.

BRECHT, Bertold. Estudos sobre teatro. Tradução: Fiamma Pais Brandão. Rio de Janeiro: Nova Fronteira, 2005.

CLIMENHAGA, Royd. Pina Bausch. Routledge, 2009.

CYPRIANO, F.; ABELLE, M. V. Pina Baush. São Paulo: Cosacnaify, 2005.

34 Disponível em: http://www.theartsdesk.com/dance/theartsdesk-qa-meeting-pina-bausch. Acesso em: 01/06/2011. Tradução da versão em inglês feita pela autora. 
DANCE DREAMS. Documentário.Written e Directed by ANNE LINSEL. Director of Photography Rainer Hoffmann BVK. Sound UWE Dresch. Co-Producer ANNE LINSEL. Producer Gerd Haag, NA Tag/Traum Production In Co Production with WDR in Collaboration with ARTE ad Dance Theater Wuppertal Pina Bausch. 89 minutes/Color/16:9. In German with Englisch subtitles.Tanzträume, 2010.

ENDICOTT, Jo Ann. Warten auf Pina - Aufzeichnungen einer Tänzerin. Henschel, 2009.

FERNANDES, Ciane. O corpo em movimento - o sistema Laban/Bartenieff na pesquisa e formação em artes cênicas. São Paulo: Annablume, 2006.

GIL, José. Movimento Total - O corpo e a Dança. São Paulo: lluminuras, 2004.

KONTAKTHOF. Schauspielhaus Wuppertal (8990). Haus Company, 2000.

KONTAKTHOF with ladies and Gentlemen over 65. A piece by PINA BAUSCH. Picture Format : 4:3/NTSC/Color. Sound Format: Dolby Digital Stereo. Menu Language: English Subtitles: English, French, German, Italien.Total Time: 149 min. L'Arche, 2007.

LABAN, Rudolf von; ULLMANN, Lisa (Org.). Domínio do Movimento. São Paulo: Summus Editorial, 1978.

LEHMANN, Hans-Thies. Teatro pós-dramático. Tradução: Pedro Süssekind. São Paulo: Cosac Naif, 2007.
LOPES, Mario. José Gil: "A inveja tem muita força em Portugal porque somos uma sociedade fechada". Tinta Fresca - jornal de arte, cultura e cidadania. Edição 53 de 21/03/2005.

Disponível em: http://www.tintafresca.net/ News/newsdetail.aspx? news $=54325 e 27-d$ 880-4809-9d64-5b2a8e050cc8\&edition=53. Acesso em: 01/02/2017.

MEDEIROS, Marina Milito de. A utilização do gestual cotidiano em Kontakthof de Pina Bausch - dan-çado por três gerações. Dissertação (Mestrado), Instituto de Artes, Universidade Estadual de Campi-nas, Campinas, 2012.

MINAYO, Maria Cecília de S. O desafio do conhecimento: pesquisa qualitativa em saúde. 3 . Ed. São Paulo: Hucitec, 1996.

MIRANDA, Rita Alves. Estudos sobre Bertold Brecht. Existência e Arte - Revista Eletrônica do Grupo PET - Ciências Humanas, Estética e Artes da Universidade Federal de São João Del-Rei. São João del-Rei, ANO VII, Número VI, janeiro a dezembro de 2011.

PAVIS, Patrice. A análise dos espetáculos. Tradução: Sérgio Salvia Coelho. São Paulo: Perspectiva, 2003.

PEREIRA, Sayonara. Rastros do Tanztheater no processo criativo de ES-BOÇO, Espetáculo Cênico com Alunos da UNICAMP. São Paulo: Annablume, 2010.

Rastros do Tanztheater em ES-BOÇO, Espetáculo Cênico com Alunos da UNICAMP. Tese (Doutorado), Instituto de Artes, Universidade Estadual de Campinas, Campinas, 2007. 
SERVOS, Nobert. Pina Bausch Dance Theatre. Munique: K. Kieser, 2008.

Recebido: $14 / 04 / 2017$

STANISLAVSKI, Constantin. A criação de um papel. Tradução: Pontes de Paula Lima. Rio de Janeiro: Civilização Brasileira, 2003a.

A preparação do ator. Tradução: Pontes de Paula Lima. Rio de Janeiro: Civilização Brasileira, 2003b.

YIN, Robert K. Estudo de Caso - planejamento e método. Porto Alegre: Bookman, 2005.

\section{Sites Acessados}

http://www.tintafresca.net/News/newsdetail.aspx? news $=54325 e 27-d 880-4809-9 d-$ 64-5b2a8e050cc8\&edition=53. Acesso em: 01/02/2017.

http://michaelis.uol.com.br/busca? $r=0 \& f=0 \&-$ $\underline{\mathrm{t}=0 \text { \&palavra }=\text { gesto. }}$. Acesso em: 01/02/2017.

http://www.theartsdesk.com/index.php?option=com k2\&view=item\&id=1260:theartsdesk-pina-bausch-interview\&ltemid=80. Acesso em: 01/02/2017.

http://www.dw.com/pt-br/pina-bausch-tudo-\%C3\%A9-dan\%C3\%A7a/a-1682335. Acesso em: 01/02/2017.

https://www.youtube.com/watch?v=eTCcRutPxZE. Acesso em:01/02/2017.

http://www.pina-bausch.de/. Acesso em: 01/02/2017. 